Journal of Computer Science 6 (5): 572-575, 2010

ISSN 1549-3636

(C) 2010 Science Publications

\title{
Proposed Movement Tracking E-Systems of Payment in the Municipalities
}

\author{
Hassan Mohammed M. Elmetwaly \\ Department of Computer Science and Information Technology, King Faisal University, \\ P.O. Box 64834, Riyadh 11546, Kingdom of Saudi Arabia
}

\begin{abstract}
Problem statement: There is no doubt that the problem of multiple entry forms data collection in information systems of the biggest problems faced by the relevant authorities. Approach: The electronic collection system proposed a final solution to the problems of collection in all municipalities. Results: Where this system was characterized by the presence of one form was linked to all information systems related to revenues. It was also a follow-up collection of the most important processes of concern to the leaders and decision makers. Conclusion/Recommendations: Through this system it can be made to extract many of the standard reports. That contained all the necessary information and follow-up the movement of collection, their impact on daily work and accelerate the transaction citizens in record time, high-speed and quality of micro databases using Oracle.
\end{abstract}

Key words: E-systems, E-archiving, ATM, E-collection, web service, XML

\section{INTRODUCTION}

Developing programming and information systems are considered the most important goals sought by everyone. Most information systems are modified and developed in order to keep up with work needs and meet the needs of all people. With regard to the wide spread of Oracle database and their qualifications, this electronic system has been designed for four years and it was updated with many developing suggestions. Our dire need to use new tools and that may help us complete all required daily works always urges us search for proper solutions with less charges. Systems' analyzers and software engineers often resort to innovate every and each new and useful things in this respect. This study discusses the mechanisms and ways of collection via this electronic system. Both the global reach and interconnectivity of the Internet have spawned new business models and radically transformed existing ones (Pant and Ravichandran, 2001), argued that e-Commerce growth would be hindered without new payment systems, some of the systems that have appeared on the market since were accompanied by exaggerated claims and unrealistic expectations or were largely inappropriate for the existing and emerging business models (Bohle, 2001), A complementary approach to improve performance is to overlap memory hierarchy accesses with computation. At the software level, recent techniques prefects known pages ahead of time (Chen et al., 2001) Database researchers propose relational processing algorithms to improve data and instruction temporal locality (Padmanabhan et al., 2001). The Web-services technology is built on the foundation of open standards and common infrastructure. The Web-services framework is divided into three areas-communication protocols, service descriptions and service discovery, of which each is specified by an open standard (Curbera et al., 2002).

\section{MATERIALS AND METHODS}

This system was designed for improving the methods of electronic collection and following up collection in municipalities. The suggested collection system has been experienced many stages. These stages are often adopted by all people interested in building information systems. First stage relates to collecting sufficient information about collection systems in municipalities through increasing the number of municipalities and noticing work on site and taking notes and enough suggestions of workers which are relevant to collection. Second stage relates to analyzing information. This stage is the most important stage of the system. Third stage relates to dividing information into two types, basic information and subsidiary information. Fourth stage relates to designing database. Fifth stage relates to building database. Sixth stage relates to building patterns which would be used by data entry officials. Seventh stage relates to building reports required to extract information. Eighth stage relates to checking and experiment. Ninth stage relates to actual running. Tenth stage relates to following up and developing. Eleventh stage of follow-up phase and development .Many of them have described the 
features of payment systems, mainly taking a technological perspective (Medvinsky and Neuman, 1993; Asokan et al., 1997). However, other factors also determine the success or failure of payment systems and not all of them are technical in nature. Technical excellence and successful implementation alone do not guarantee widespread adoption. Customer and merchant acceptance also depends on many user-related and market related issues which the developers of a payment system need to consider. Therefore, to better understand how payment systems are perceived by the various stakeholders and the features that impact on them, it is essential that all these aspects be considered for a more comprehensive understanding of the problems and challenges facing payment systems. The characteristics that describe these systems can be defined from various points of view that include user related, technical, market, legal and other categorizations (Abrazhevich, 2001). First of all, electronic fund transfers in retail payment systems are not as widely used as in large-value payment systems. There are two operational structures in the form of correspondent (or network) and tiered relationships for large value fund transfers, but only correspondent (or network) relationships are active for electronic fund transfers in retail payment systems. As such, electronic fund transfers in retail payment systems should be handled within the framework of correspondent relationships between banks or their branches. Especially concerning cross-border or international correspondent relations, some forms of consolidation have been developed by financial institutions, banks or postal institutions (Sit, 2005).

\section{RESULTS}

- One model from which all collection processes can be entered

- Methods for easy and quick search for searching any data entered into the system during a period of time specified by the user

- Help tools for converting Gregorian date to Hijri date and vice versa

- The facility of opening new financial year without closing the previous one

- Controlling the authorities of users

- Exporting reports to several formats including Excel, Word and XML

- The facility of making back-ups automatically for database in a specific time

- This system can run on local and international networks

- Extracting many reports
- The E-system support dealing with touch screens

\section{DISCUSSION}

This system has been built and designed to solve the problem of collecting in municipalities, its database have been built by using Oracle (SQL). The used programming language is Oracle Developer. Figure 1 shows the movement of electronic system and how it connects with Oracle database and other information systems. Figure 2 includes entry sample and following up collection by users of such system and they can enter data through local network or the internet according to authorities they are granted. The customer may pay the required fees electronically through ATM machines all over the world. There are a large number of reports which show daily, monthly and yearly collection. This helps follow up and support taking decision.

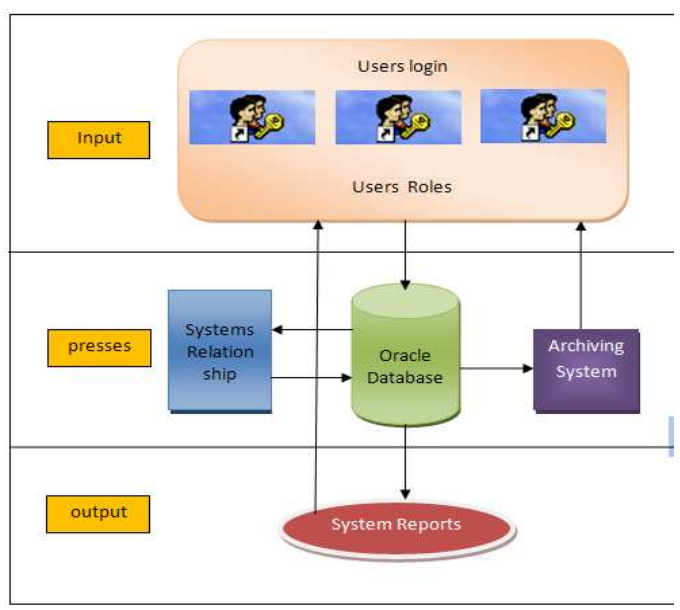

Fig. 1: Architecture of the payment system

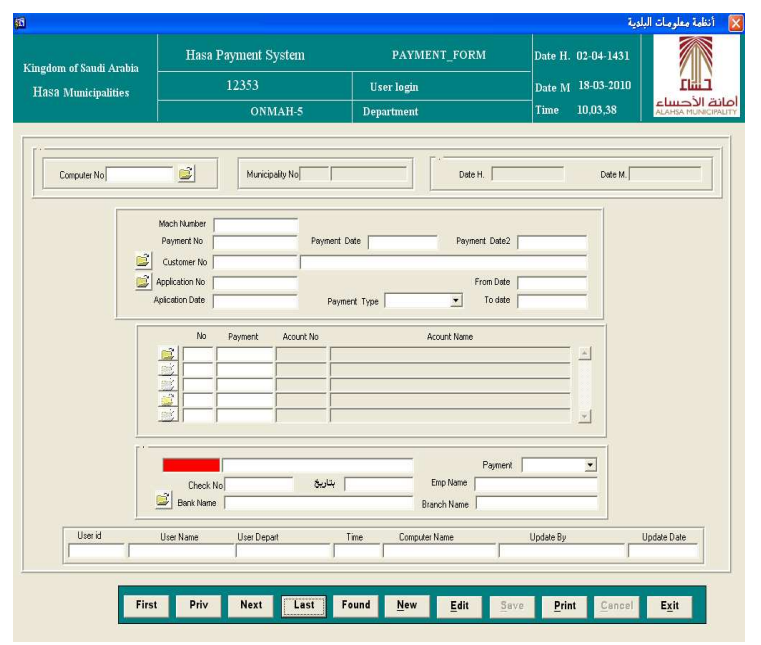

Fig. 2: Main form of E-payment system 


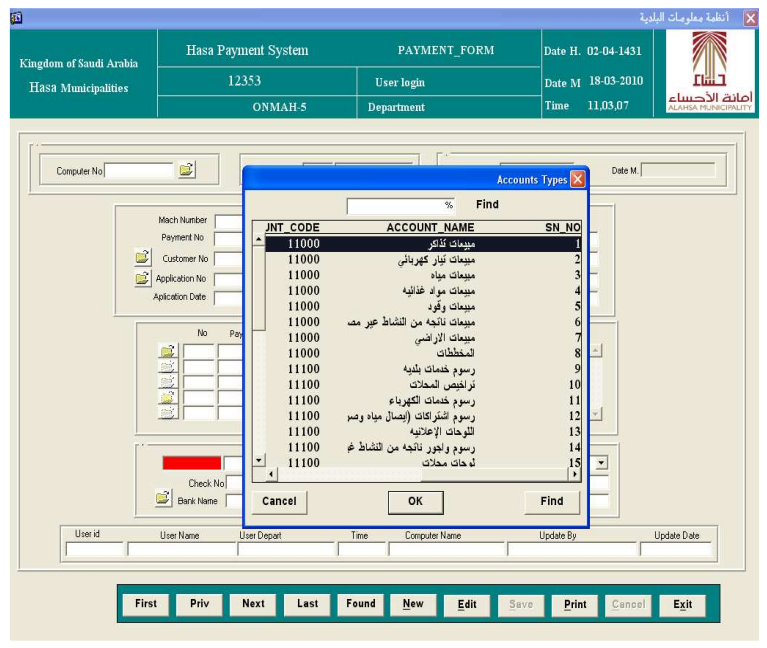

Fig. 3: The different types of accounts

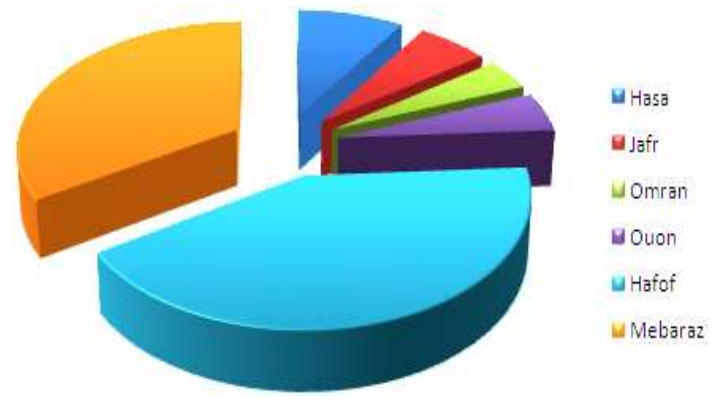

Fig. 4: Size of collections by regions

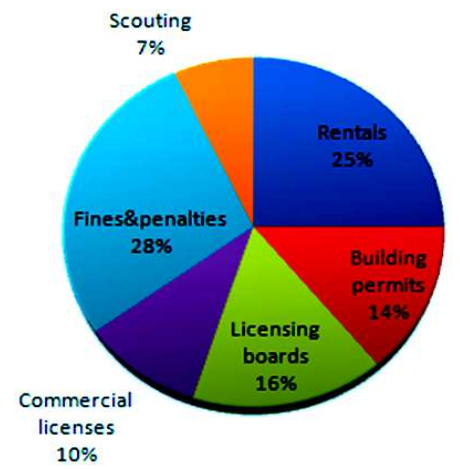

Fig. 5: Type of accounts report

Figure 3 shows the way of presenting types of different accounts and choosing among them during the process of entering data. Figure 4 shows a report of types of collection and divided according to their volume. Figure 5 discusses a report of collection volume according to regions and cities. Figure 6 shows the total of revenues and the rate of collection growth in municipalities. Figure 7 shows the streamlined drawing of the suggested system for information systems.

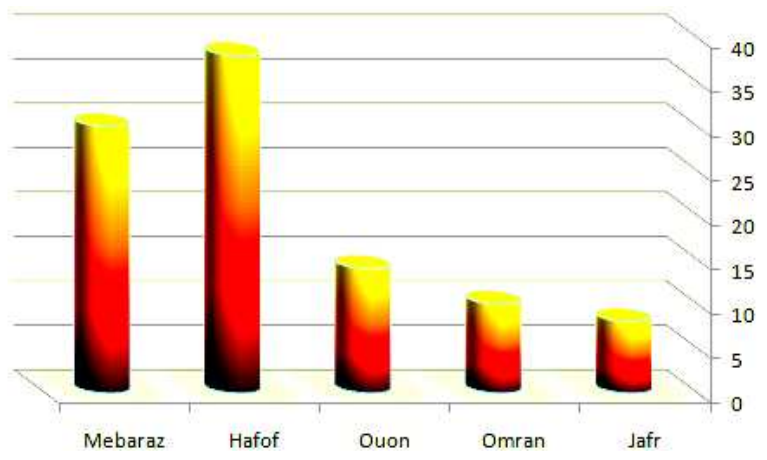

Fig. 6: The total accounts for areas

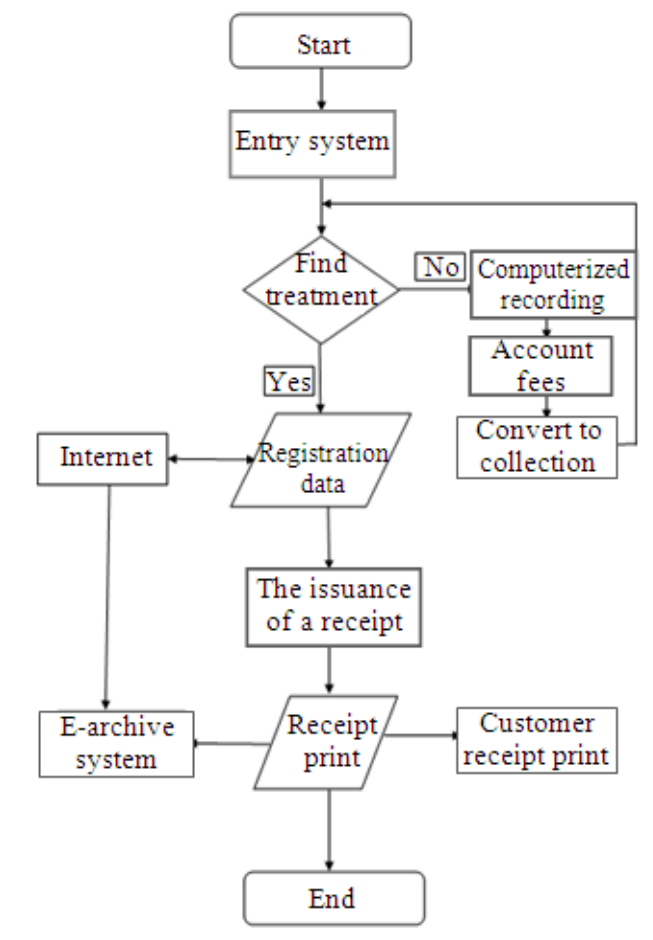

Fig. 7: System flow chart

\section{CONCLUSION}

The substantial goal of electronic collection system is to enter and follow up the collection movement in all municipalities, in addition to extracting many reports and diagrams. This electronic system can also help follow up collection processes after saving them on computer and supply with all database related to required information. Moreover, such system may help make financial analysis for financial menus and evaluate performance. This system depends on Oracle database to store and recover data. It is well known that Oracle database are the best ones since they are 
characterized by high speed and indefinite accuracy in editing and presenting data in a form of reports. There is a great flexibility in changing the form of printed reports in a way that suits the performance of user. This system is characterized also by adding any unlimited number of users and controlling the authorities of users. This new system has been experienced in many municipalities in Saudi Arabia and has achieved a remarkable success and wonderful results.

\section{REFERENCES}

Abrazhevich, D., 2001. Classification and characteristics of electronic payment systems. Lecturer Notes Comput. Sci., 2115: 81-90.

Asokan, N., P.A. Janson, M. Steiner and M. Waidner, 1997. The state of the art in electronic payment systems. IEEE Comput., 30: 28-35.

Bohle, K., 2001. On hype, sacred cows, data holes and how to cope with them. Electronic Payment Systems Observatory-Newsletter. http://epso.jrc.es/newsletter.

Curbera, F., M. Duftler, R. Khalaf, W. Nagy, N. Mukhi and S. Weerawarana, 2002. Unraveling the web services web-an introduction to SOAP, WSDL and UDDI. IEEE Internet Comput., 6: 86-93. http://direct.bl.uk/bld/PlaceOrder.do?UIN=110521 $303 \&$ ETOC $=\mathrm{RN} \&$ from $=$ searchengine
Chen, S., P.B. Gibbons and T.C. Mowry, 2001. Improving index performance through prefetching. ACM SIGMOD Rec., 30: 235-246. http://portal.acm.org/citation.cfm?id=375688

Medvinsky, G. and B.C. Neuman, 1993. NetCash: A design for practical electronic currency on the Internet. Proceeding of the 1st ACM Conference on Computer and Communication Security, Nov. 3-5, ACM Press, Fairfax, Virginia, United States, pp: 102-106.

http://portal.acm.org/citation.cfm?id=168588.168601

Padmanabhan, S., T. Malkemus, R. Agarwal and A. Jhingran, 2001. Block oriented processing of relational database operations in modern computer architectures. Proceedings of the 17th International Conference on Data Engineering, Apr. 2-6, IEEE Computer Society, Washington DC., USA., pp: 567. http://portal.acm.org/citation.cfm?id=879677

Pant, S. and T. Ravichandran, 2001. A framework for information systems planning for e-business. Logist. Inform. Manage., 14: 85-98.

Sit, B., 2005. Basic Electronic Payment Systems and Determination of the Applicable Law in North America and Europe. 